\title{
Adapting to an irrelevant item in an immediate recall task
}

\author{
MICHAEL J. WATKINS and ELIZABETH S. SECHLER \\ Rice University, Houston, Texas
}

\begin{abstract}
Recall of the last one or two items of a spoken list is impaired when the list is followed by a nominally irrelevant item. At issue here was whether this suffix effect is reduced with repeated exposure to the irrelevant item. The effect was found to decline over successive blocks of trials, but only slightly (Experiment 1). No decisive evidence for adaptation to the irrelevant item was found when it was spoken after each of the list items rather than after the last one only (Experiments 2 and 3). The strongest evidence for adaptation was obtained when the irrelevant item was repeated in an unbroken stream that extended through the presentations and recall periods of successive lists: The recency effect and the level of recall at the last position within a list were greater under these conditions than when the irrelevant item was presented only once after each list (Experiments 4, 5, and 6).
\end{abstract}

Postbehaviorist conceptions of memory tend to neglect the stimulus as a source of control over the remembering process. For perceivable stimuli, our powers of attention and organization and rehearsal are seen as overshadowing any effects of the physical aspects of the stimuli. We are therefore considered to have more or less complete control over what is and what is not remembered.

As has been argued elsewhere (M. J. Watkins, 1989), there are problems with this perspective. A particularly striking problem arises in experimental procedures in which a to-be-recalled list of spoken items is followed by a spoken item that is nominally irrelevant to the subjects' task: The subjects appear unable to ignore this item, for it sharply reduces the probability of recall for the last one or two items of the to-be-recalled list (Crowder \& Morton, 1969). Indeed, some studies have found that the suffix item impairs recall of the preceding items just about as much as does an additional to-be-remembered item (Crowder, 1967, Experiment 3; Dallett, 1965). To be sure, the effect of the suffix item is lessened if it occurs in a voice (Greenberg \& Engle, 1983; Morton, Crowder, \& Prussin, 1971, Experiments 14 and 15; O. C. Watkins \& M. J. Watkins, 1980, Experiment 3) or comes from a direction (Morton et al., 1971, Experiments 2, 7, and 8) that is different from that of the to-be-remembered list items, but by and large it is remarkably robust.

The research was supported by National Institute of Mental Health Grant MH35873. We thank Michael Gemar for testing some of the subjects in Experiment 1 and Ian Neath for writing the computer programs for list presentation in Experiments 5 and 6. Elizabeth Sechler is now at Belmont Abbey College. Correspondence concerning this article should be addressed to Michael J. Watkins at the Department of Psychology, Rice University, P. O. Box 1892, Houston, TX 77251.
Why should we have so much trouble ignoring a suffix item when we are capable of functioning in a world that bombards us with a vast array of irrelevant stimuli? The purpose of this article is to explore the possibility of resolving this paradox by invoking the concept of adaptation-by appealing to the commonplace that even if a stimulus commands our attention on initial exposure, it may relinquish its hold as exposure increases. The ticking of a clock or the hum of a fan engages us initially, but soon frees us to concentrate on something else. In a more formal vein, research shows that stimuli having nominally irrelevant features tend to be classified faster if the irrelevant features are exposed beforehand (Lorch, Anderson, \& Well, 1984). Adaptation to irrelevant information might similarly be inferred from findings that performance on the Stroop task improves with practice (Reisberg, Baron, \& Kemler, 1980; Stroop, 1935). Particularly relevant to the present purpose is evidence that adaptation can occur to irrelevant spoken information: The ability to solve arithmetic problems presented in a male voice while nominally irrelevant information is heard in a female voice has been found to be enhanced by prior exposure to the female voice (Waters, McDonald, \& Koresko, 1977).

In the present study we sought evidence for adaptation to the suffix item. In each of six experiments we inquired whether exposure to the suffix item would diminish its effect. The idea behind Experiment 1 was simply to see whether the magnitude of the suffix effect would decrease over the course of a sequence of lists. In Experiments 2 and 3 we examined the effect of presenting the suffix item not only in its regular suffix position at the end of the list, but after each list item. In Experiments 4, 5, and 6 we further intensified exposure to the suffix item by presenting it throughout both list presentations and the recall intervals between the lists. 


\section{THE SUFFIX EFFECT OVER THE COURSE OF A SEQUENCE OF LISTS}

\section{Experiment 1}

If adaptation can occur to a suffix item, then the suffix effect might be expected to diminish over the successive list presentations of a typical testing session; however, evidence on this point is sparse and inconclusive. Crowder (1969) found no significant evidence for a decline in the suffix effect even after extensive practice, whereas Balota and Engle (1981) found that practice reduced the effect of a suffix item on preterminal items (specifically, items presented in Positions 3-6 of a 7-item list) but not on the last item. Penney (1985, Experiment 1), by contrast, found that practice reduced the effect of the suffix at the last position, although she failed to replicate this result in a second experiment (her Experiment 2); for preterminal positions, she found an influence of practice on the suffix effect only in the form of higher order interactions.

The present experiment was intended to shed a little more light on this confusing situation. The subjects were required to reproduce 9-digit lists. They were tested on both a sequence of suffix lists and a control sequence of no-suffix lists, the order of these sequences being counterbalanced. At issue was whether recall of the last one or two digits of the lists would gain more over the course of the suffix sequence than over the course of the control sequence.

\section{Method}

Stimulus lists. The stimulus lists consisted of the digits 1 through 9 in an order that was random within the constraint that consecutive digits (e.g., 6, 7) not occupy adjacent list positions either in forward $(6,7)$ or in backward $(7,6)$ order. The suffix item was "zero." In all, there were 56 such lists, 54 for the experiment proper and 2 for practice. The lists were presented in a synthetic male voice (the "bass" voice of "Smoothtalker," distributed by First Byte,
Inc.) on an Apple Macintosh 512 microcomputer. The digits occurred at 1-sec onset-to-onset intervals with, in the case of the suffix condition, the zero occurring $1 \mathrm{sec}$ after the onset of the last to-beremembered digit.

Design. Aside from the practice lists, 27 lists were presented in the control condition and 27 in the suffix condition. Half of the subjects received the control lists before the suffix lists, and half received the suffix lists before the control lists. Within each of these groups of subjects, the ordering of the individual lists was counterbalanced across three subgroups of 16 subjects according to a Latin square so that each block of nine lists occurred equally often as the first, second, and third block within each of the two conditions. For the purposes of analysis, there were two within-subjects factors, namely list condition (no-suffix or suffix) and position within the testing sequence (first, second, or third block within a condition).

Subjects. The subjects were 96 Rice University undergraduates.

Procedure. Some subjects were tested individually, others in small groups. To familiarize the subjects with the synthetic speech used to present the lists, we first required them simply to copy four lists while they were being presented. These lists consisted of random permutations of the digits 0 through 9 , and they were presented at a rate of one digit every second. Two subjects each made one error on the first of these lists, but otherwise the responses were correct.

The experiment itself involved the presentation of a long sequence of digit lists, with the lists of either the first or second half of the sequence being followed by a nominally irrelevant zero. Successive lists were separated by a $21-\mathrm{sec}$ recall interval, after $15 \mathrm{sec}$ of which the experimenter signaled the upcoming list by saying "Ready." The subjects wrote their responses on sheets that had been ruled with rows of nine short lines. They were required to record the digits in presentation order, beginning with the first digit in the leftmost space and ending with the last digit in the rightmost space; when they could not recall a digit, they were to respond with a dash. Responding was monitored to ensure compliance with the instructions. Each half of the sequence was preceded by a control or suffix practice list, as appropriate, and by an invitation for questions.

\section{Results and Discussion}

Before presenting the results of this experiment we need to comment on the way in which, for the entire series of experiments, the effect the suffix item had on recall of

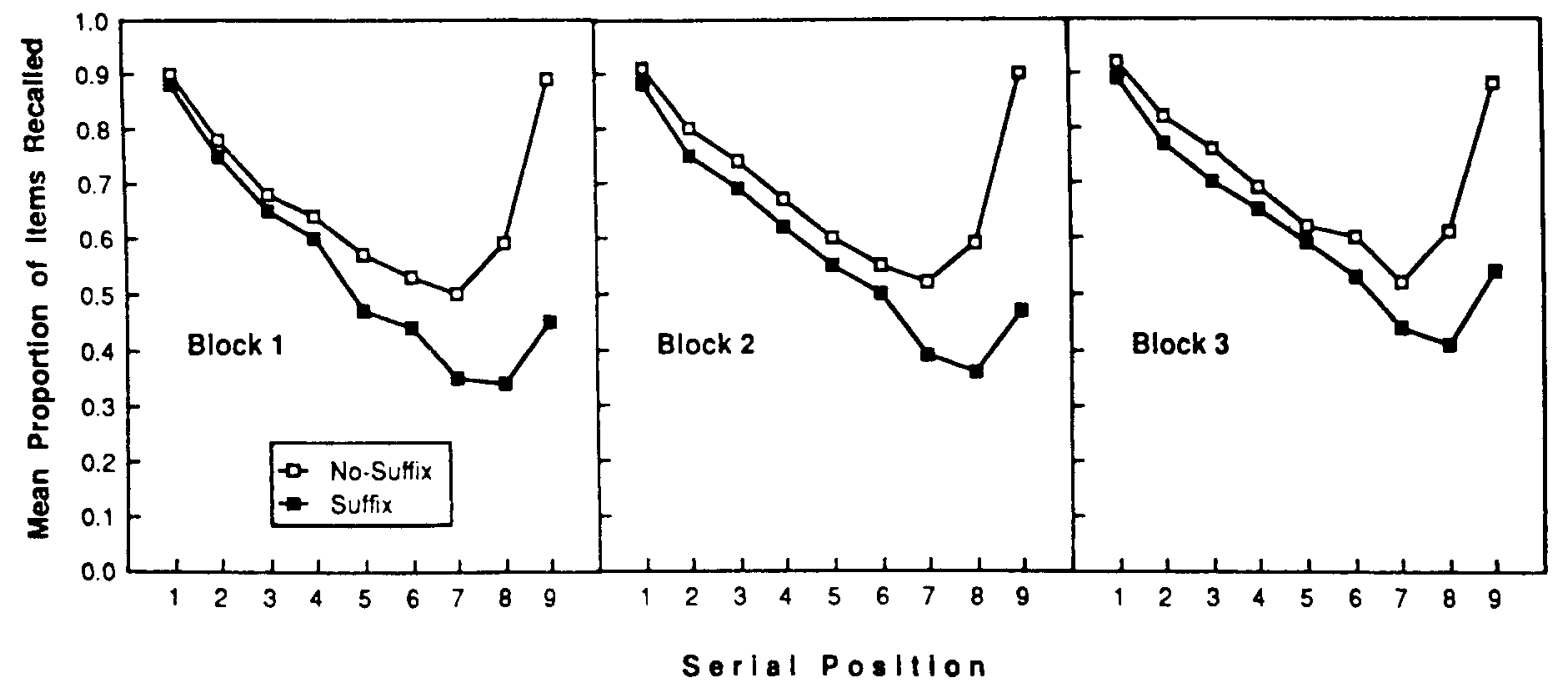

Figure 1. Mean proportion of items recalled in correct position as a function of serial position, suffix condition, and list block (Experiment 1). 
the last few list items was operationalized for the purpose of data analysis. To capture recency recall we used two measures, the first pertaining to the trend in recall across the last part of the serial position curve and the second to level of recall at just the last serial position.

For the first, or recency-trend, measure, we defined the effect of the suffix item as the magnitude of the recency trend in the no-suffix control condition minus the magnitude of the recency trend in the suffix (or other irrelevantitem) condition. All of the experiments we report here involved nine-item lists, and for this list length the results of published studies more often than not show the low point of the serial position curve for the no-suffix control condition to be at the seventh position (e.g., Crowder, 1967, Experiment 3; Crowder \& Morton, 1969, Experiment 2; Morton et al., 1971, Experiments 3, 13, and 14; Routh \& Frosdick, 1978, Experiment 5; Salamé \& Baddeley, 1982, Experiments 3, 4, and 5). Consequently, we defined the magnitude of the recency trend as the proportion of items recalled at the ninth serial position minus the proportion recalled at the seventh position. Our second measure was simply the probability of recall at the ninth position of the no-suffix condition minus the corresponding probability for the suffix (or other irrelevantitem) condition. This last-position measure complements the recency-trend measure in two important respects. First, it is in keeping with the growing conviction (e.g., Baddeley \& Hull, 1979; Balota \& Engle, 1981; Morton, Marcus, \& Ottley, 1981; Penney, 1985) that the effect of the suffix item on the last position is of particular theoretical significance. Second, it deals with absolute levels of performance rather than with position-to-position differences in levels of performance. The inferential analyses based on these two measures should be interpreted in the context of the serial position functions, which are displayed graphically for each experiment; the numerical values of the two measures are given in the Appendix.

The results of the first experiment are summarized in Figure 1. Each panel refers to a block of lists within the no-suffix and suffix conditions, and it shows for these conditions the mean proportion of items recalled at each serial position. Clearly, there was a marked suffix effect for all three list blocks, but it is not so clear whether the suffix effect declined from the first list block to the third.

An analysis of the recency-trend data showed no reliable change across list blocks. It revealed a difference between conditions $\left[F(1,95)=150.49, M S_{\mathrm{e}}=.063\right.$, $p<.001$ ], indicating the presence of a suffix effect, but no difference among blocks $\left[F(2,190)=0.54, M S_{\mathrm{e}}=\right.$ $.016]$. Most importantly, it showed no reliable interaction between condition and block $\left[F(2,190)=0.50, M S_{\mathrm{e}}\right.$ $=.036$.

Analyses based on the last-position measure were a bit more supportive of the adaptation hypothesis. Thus, whereas in the control condition the proportion of items recalled at the last position remained fairly constant across blocks, in the suffix condition it increased (see Appendix). An analysis of variance indicated reliable effects of condition $\left[F(1,95)=401.99, M S_{\mathrm{e}}=.057, p<.001\right]$ and block $\left[F(2,190)=4.64, M S_{\mathrm{e}}=.046, p<.02\right]$, and, importantly, a reliable interaction between condition and block $\left[F(2,190)=7.57, M S_{\mathrm{e}}=.018, p<.001\right]$. This interaction was substantially accounted for by a difference between the conditions in the linear component of trend across blocks $[t(95)=3.47, p<.001] .{ }^{1}$ Of course, even in the third block, there remained an appreciable and statistically significant advantage for the no-suffix condition $[t(95)=13.79, p<.001]$.

The evidence this experiment provides for the notion that one can adapt to the suffix item is at best modest. The recency-trend measure provided no evidence at all for adaptation: increasing exposure to the suffix item resulted in no significant gain in recency trend in the suffix condition over that which occurred in the no-suffix condition. The last-position measure did show that performance in the suffix condition gained on that in the nosuffix condition across successive blocks of lists. However, the gain was rather small, and it conflicted with previous findings (Balota \& Engle, 1981; Penney, 1985, Experiment 2). Clearly, a convincing demonstration of adaptation to the suffix items requires a different approach.

\section{THROUGH-LIST PRESENTATION OF THE NOMINALLY IRRELEVANT ITEM}

Perhaps Experiment 1 failed to produce more impressive evidence for adaptation because the presentation schedule of the nominally irrelevant item was unsuitable. The irrelevant item occurred only once with each list presentation, for a rate of one occurrence approximately every $30 \mathrm{sec}$. Adaptation to a clock that ticked at such a rate might also be difficult. In the following two experiments the irrelevant item was presented not just in the regular suffix position, but after each item of the list. Of interest was whether this more intensive exposure schedule would enhance recency recall.

We should note that this procedure is formally similar to one known as the through-list (or continual) distractor procedure, in which subjects study a list of words for recall and engage in a distractor task after the presentation of each word (or each pair of words). The distractor task typically involves counting backward by threes for several seconds. It has long been known that if given after only the last item of the list, this task has the effect of virtually eliminating the recency effect (Glanzer \& Cunitz, 1966; Postman \& Phillips, 1965). When, however, it is given throughout list presentation as well as at the end of the list, the recency effect reemerges (Bjork \& Whitten, 1974; Tzeng, 1973). In other words, the damaging effect of postlist distractor activity on recall of the last few items can be avoided, or at least sharply attenuated, by requiring that the distractor activity also be performed throughout list presentation. Such a procedure differs from the procedure of the following two experiments in its explicit requirement that the interpolated 
material be attended to. Nevertheless, the data it generates are certainly consistent with the notion of adaptation to distractor material.

A search of the literature turned up two experiments specifically relevant to the question of whether presentation of a to-be-ignored item throughout the list as well as immediately following the list helps bring back the recency effect. The findings from these two experiments are somewhat inconsistent. In one, reported by Hitch (1975, Experiment 2), subjects were tested on serial recall of digit lists in three conditions pertinent to the present purposes: a standard suffix condition, a no-suffix control condition, and a through-list condition in which the item serving as the suffix was presented after each of the preterminal list items as well as in the regular suffix position. The critical comparison, namely that between the throughlist and standard suffix conditions, was not formally made by Hitch, but it can be made in a qualitative way by superimposing serial position functions from two of the panels of his Figure 2. As near as can be discerned, neither the recency-trend nor the last-position recall differed to any marked extent between the two conditions. On the other hand, the results of an experiment briefly reported by Kahneman and Henik (1981, Experiment 9) suggest that through-list presentation of a nominally irrelevant item may have enhanced last-position recall. The experiment included the same three conditions used in the Hitch experiment, although this time the irrelevant item was heard from a different speaker from the one used for the to-be-remembered items. Kahneman and Henik reported recall performance only for the last position, and although they reported no statistical analysis, the proportion of items recalled at this position was higher in the through-list suffix condition (.94) than in the standard suffix condition (.87).

More complete evidence on the effect of through-list exposure to the irrelevant item was sought in the following two experiments.

\section{Experiment 2}

In essence, subjects engaged in a serial recall task under each of three conditions: a no-suffix control condition, in which only to-be-remembered digits were presented; a standard suffix condition, in which a nominally irrelevant zero was presented after just the last tobe-remembered digit; and a through-list condition, in which the irrelevant zero was presented after each of the to-be-remembered digits. The question of interest was whether recall of the last one or two digits would be enhanced by presenting the irrelevant item after each digit rather than just the last one.

\section{Method}

Stimulus lists. The stimulus lists consisted of the digits 1 through 9 arranged in the quasi-random order described under Experiment 1. A total of 51 lists were prepared, 45 for the experiment proper and 6 for practice.
The lists were recorded on audio tape in a female voice, with a separate recording being made for each of the three subject groups used to counterbalance order and condition. For all conditions the to-be-remembered digits occurred at a rate of one per second. For the standard suffix condition the onset of the irrelevant zero occurred $0.5 \mathrm{sec}$ after the onset of the last digit of each list, and for the through-list condition it occurred $0.5 \mathrm{sec}$ after the onset of each digit, including the last.

Design. For the experiment proper, all subjects were presented with the same sequence of 45 to-be-remembered lists. The condition was changed after 15 lists and then again after another 15 lists, so that the same number of lists were recalled under each of the three conditions. The order of the conditions was varied among three equal-sized groups of subjects according to a Latin square, so that across all subjects each set of 15 lists occurred equally often in each condition, and each condition was represented equally often in the beginning, middle, and end portions of the testing sequence.

Subjects. The subjects were 21 Rice University undergraduates.

Procedure. The subjects were tested in small groups. They were presented with a long sequence of digit lists played on a tape recorder, and were told to ignore all presentations of the item zero and to concentrate on recalling the digits 1 through 9 in their order of presentation. Details of the recall instructions were as in Experiment 1 . The list sequence was blocked by condition and, prior to each block, the condition of the upcoming lists was described and two practice lists were presented.

\section{Results and Discussion}

The results are summarized in Figure 2. A comparison of the standard suffix and no-suffix control curves shows a typical suffix effect, with level of performance being lower in the standard suffix condition, especially near the end of the list. The no-suffix control condition

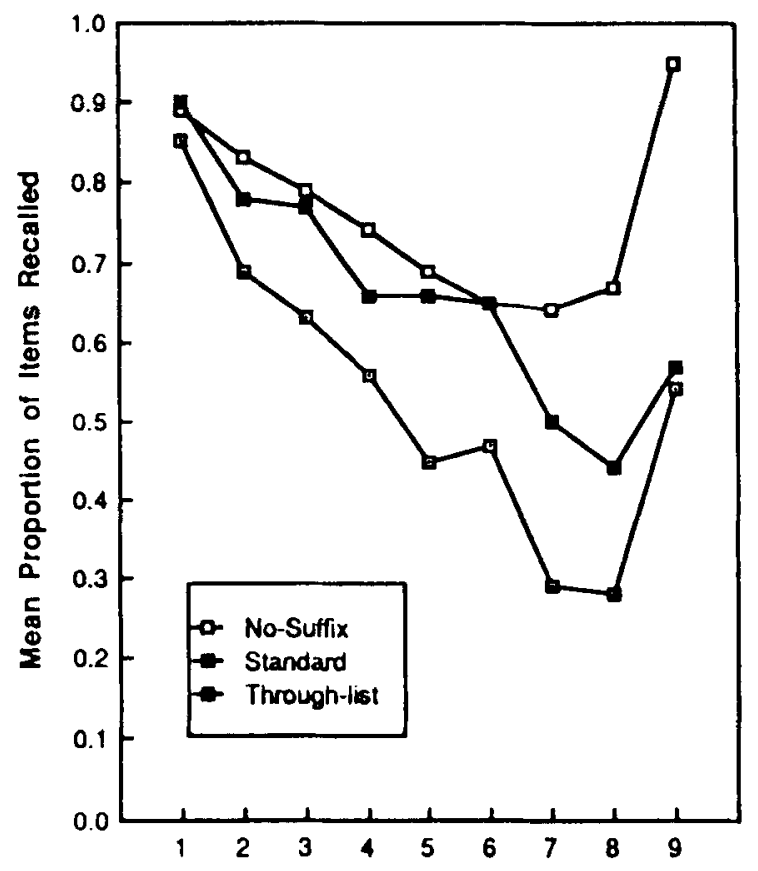

Serial Position

Figure 2. Mean proportion of items recalled in correct position as a function of serial position and suffix condition (Experiment 2). 
showed a reliable advantage with both the recency-trend measure $[t(20)=4.06, p<.001]$ and the last-position measure $[t(20)=8.76, p<.001]$, these measures being defined as in Experiment 1.

Of more concern here is how performance in the through-list condition fitted into the picture. As Figure 2 makes plain, performance in this condition was not only lower than in the no-suffix control condition, but also lower than in the standard suffix condition. The impairment relative to the standard suffix condition was not evenly distributed across the serial positions, for the recency trend was sharper in the through-list condition $[t(20)=4.07, p<.01]$. Indeed, the recency trend was only slightly and not reliably smaller in the through-list condition than in the no-suffix control condition $[t(20)=$ .92]. Nevertheless, absolute level of recall in the throughlist condition was no higher than in the standard suffix condition even at the last serial position; in fact, it was slightly-though not reliably $[t(20)=.74, p>.10]-$ lower. Of course, last-position recall was reliably lower in the through-list condition than in the no-suffix control condition $[t(20)=10.54, p<.001]$.

It would appear, then, that presenting the irrelevant item after each list item rather than after only the last one enhances the recency trend but does not give rise to a greater absolute level of recency recall.

\section{Experiment 3}

In the preceding experiment we assumed that the nominally irrelevant item was the same for the through-list condition as for the standard suffix condition. Certainly, it was zero in both cases, but it is conceivable that its repeated presentation in the through-list condition resulted in its utterance in the critical suffix position being subtly different from its utterance in the standard suffix condition. The procedure was replicated in the present experiment in a way that precluded the possibility of such a confound: The stimuli were all presented in synthetic speech, thereby ensuring that all utterances of the irrelevant item were physically identical.

\section{Method}

The method was the same as that of Experiment 2 with the exception that the stimuli, both the to-be-remembered list items and the nominally irrelevant zero, were presented in synthetic speech. The details of the stimuli and their recording are as described in Experiment 1.

The subjects were 18 Rice University undergraduates.

\section{Results and Discussion}

The data are summarized in Figure 3. Note that overall level of recall was somewhat lower than in the previous experiment. Presumably, this reduction was the result of switching from natural to synthetic speech, for although each item was clear enough to be identified, synthetically presented lists do seem to require more attention.

In other respects, the results closely resemble those of Experiment 2. There was a regular suffix effect, with level of recall toward the end of the list being sharply lower in the standard suffix condition than in the no-suffix control condition. Statistical analyses confirmed the advantage of the no-suffix control condition for both the recency-trend measure $[t(17)=5.03, p<.001]$ and the last-position measure $[t(17)=7.75, p<.001]$.

Performance in the through-list condition revealed a recency trend that was more pronounced than in the standard suffix condition $[r(17)=2.96, p<.01]$, although less pronounced than in the no-suffix control condition $[t(17)=2.65, p<.02]$. Even by the last position, however, probability of recall in the through-list condition was only trivially, and certainly not reliably $[t(17)$ $=.63, p>.10]$, higher than in the standard suffix condition, and it was, of course, substantially lower than in the no-suffix control condition $[t(17)=7.75, p<.001]$.

In both this experiment and the previous one, presenting an irrelevant item after every list item proved to be less detrimental to the recency trend than did presenting it after only the last item. On the other hand, it appreciably impaired overall level of recall, so that probability of recall was no greater than in the standard suffix condition even at the last position. Consequently, the sharper recency effect in the through-list condition could be attributed just as readily to an impairment in recall for items prior to the last one as to adaptation to the suffix item. The case for adaptation to an irrelevant item would clearly be stronger if the most intensive schedule of exposure to the irrelevant item resulted in not only a more pronounced

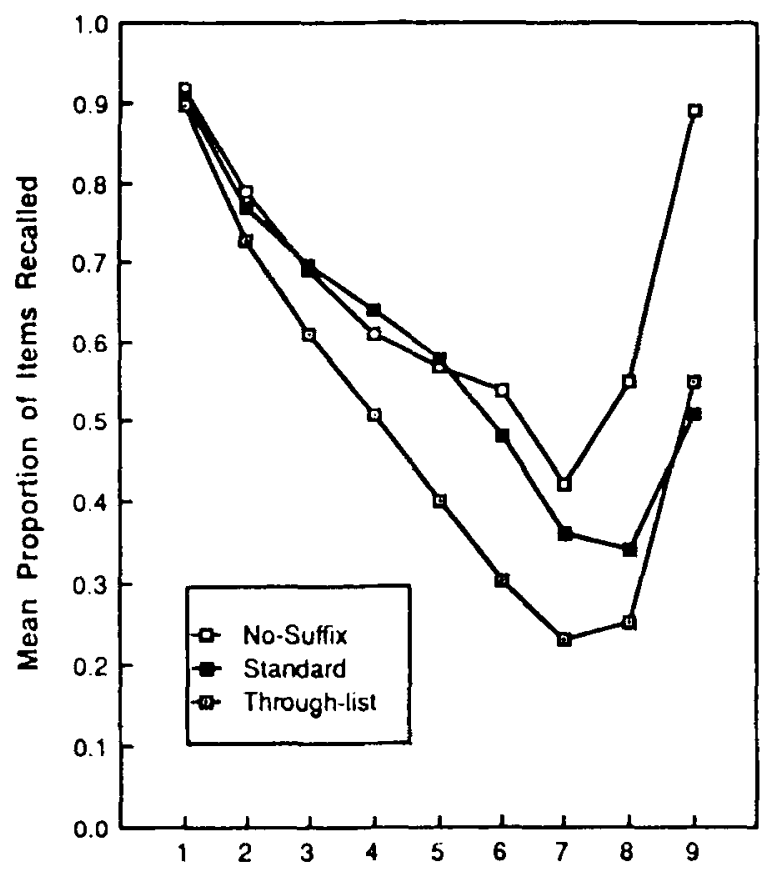

Serial Position

Figure 3. Mean proportion of items recalled in correct position as a function of serial position and suffix condition (Experiment 3). 
recency trend but also a higher absolute level of recency recall. It was in search of such a result that we conducted the remaining three experiments.

\section{CONTINUOUS PRESENTATION OF THE NOMINALLY IRRELEVANT ITEM}

In Experiment 1, the nominally irrelevant item was presented only once every $30 \mathrm{sec}$ or so. In Experiments 2 and 3 , it occurred more frequently, but in all likelihood this presentation schedule was still not as conducive to adaptation as it might be: The clock ticked more quickly, but it kept stopping. In the remaining three experiments, the clock was made to run at the same comparatively fast rate but without stopping. In other words, a regular and unbroken sequence of zeros extended through both the presentation and recall intervals of successive lists, beginning before the first item of the first list and ending at the conclusion of the recall period of the last list. Recall in this condition was compared with that in both a nosuffix condition and a standard suffix condition.

In addition to these three conditions, a triple suffix condition was included. This condition was like the standard suffix condition except that the suffix item was presented three times in succession rather than just once. Its inclusion was prompted by findings that a triple suffix impairs the recency effect less than does a conventional single suffix (Crowder, 1978, Experiments 1 and 1a; Morton, 1976, Experiments 3 and 4). Thus, we added the triple suffix condition to check that whatever enhancement in recency recall occurred with the continuous presentation procedure was not attributable solely to the first two additional presentations of the suffix item at the beginning of the recall period.

\section{Experiment 4}

In the previous three experiments, the nominally irrelevant item, whether presented in the suffix position or among the list items, was always in the same voice as the list items. This was not the case in the present experiment: all list items were presented in a female voice and all presentations of the nominally irrelevant zero were in a male voice. Because such physical characteristics as voice quality can be used in directing attention (Broadbent, 1952; Treisman, 1964), we had a hunch-probably ill-founded, as it turned out-that a physical distinction between the suffix item and the list items would enhance adaptation.

\section{Method}

Stimulus lists. The stimulus lists were as in the previous experiments. This time, however, there were four sets of 21 lists, with the first list of each set being used for practice. For each of the 84 lists, four versions (no-suffix control, standard suffix, triple suffix, and continuous presentation) were prepared in such a way that the same physical recording of each list was used for each version, and all presentations of the zero were from the same utterance. This was accomplished with the aid of a Tascam Ministudio cassette recorder, a device that allows merging of independently recorded tracks. The to-be-remembered digits occurred at a rate of one every second. Successive lists were separated by a recall interval of $15 \mathrm{sec}$, with the warning "Ready" being spoken $10 \mathrm{sec}$ into the interval. Hence the onset of each of the list items and of the warning signal were all separated from one another by multiples of $1 \mathrm{sec}$. Any given presentation of the zero, whether located within or between list presentations, was displaced from any given list item or from the warning signal by $(n+0.5)$ sec. In particular, for the standard suffix condition the zero began $0.5 \mathrm{sec}$ after the onset of the last list item; for the triple suffix condition it was added three times at 1 -sec intervals, with the first beginning $0.5 \mathrm{sec}$ after the onset of the last list item; and for the continuous presentation condition it occurred at a $1-\mathrm{sec}$ rate in an uninterrupted sequence that began $9.5 \mathrm{sec}$ before the first item of the first list and continued in exact alternation with the to-be-remembered items of each list until the end of the recall interval of the last list.

Design. All subjects heard the same sequence of 84 lists, with each successive block of 21 lists occurring in a different condition. The assignment of blocks to conditions was varied among four equalsized groups of subjects according to a Latin square, so that each list occurred equally often in each condition and each condition occurred equally often in each quarter of the testing sequence.

Subjects. The subjects were 20 Rice University undergraduates.

Procedure. Some subjects were tested in small groups, others by themselves. The instructions and general testing procedures were the same as in the previous experiments, with the subjects being told to ignore any zeros and to recall the list items in their presentation order.

\section{Results and Discussion}

The results of main concern, namely those of the nosuffix control condition, the standard suffix condition, and

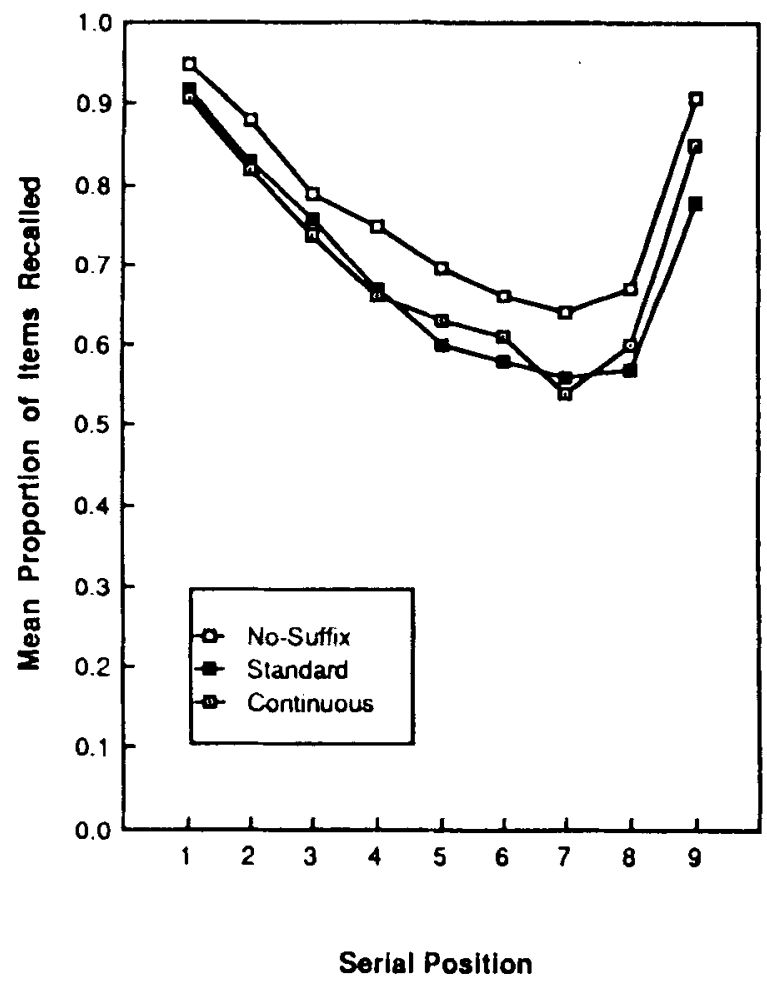

Figure 4. Mean proportion of items recalled in correct position as a function of serial position and suffix condition (Experiment 4). 
the continuous presentation condition, are summarized in Figure 4. Those for the triple suffix condition turned out to be unimportant for the present purposes, and their summary will be deferred until after consideration of the results of the other conditions.

It is clear from Figure 4 that overall level of recall is rather high. Also, a comparison of the no-suffix control condition and the standard suffix condition reveals little by way of a regular suffix effect. To be sure, level of recall was lower in the standard suffix condition, and reliably so at the final list position $[t(19)=3.91, p<.001]$. The distribution of the effect of the suffix across list positions was surprisingly uniform, however, and the recency trend was only slightly, and not reliably, smaller in the standard suffix condition than in the no-suffix control condition $[t(19)=1.14, p>.10]$.

Of more interest is the comparison between the results of the standard suffix condition and those of the continuous presentation condition. In the first place, overall level of recall in the continuous presentation condition (.71) was no lower than that in the standard suffix condition (.69). Thus, compared to recall in the no-suffix control condition (.77), recall was appreciably reduced by a single utterance of the irrelevant item, but adding 23 more utterances of the same item resulted in no further reduction. Remember, too, that in Experiments 2 and 3, overall level of recall was appreciably lower in the through-list condition than in the standard suffix condition. That there was no comparable impairment in the present experiment is consistent with the notion that repeating the irrelevant item throughout the recall interval as well as throughout list presentation serves to foster adaptation.

Also consistent with the notion of adaptation to the irrelevant item, the recency trend (defined as in Experiment 1) was greater in the continuous presentation condition than in the standard suffix condition. Given the uncharacteristically sharp recency trend in the standard suffix condition, however, this trend advantage was small and not statistically significant $[t(19)=1.70, p<.05]$. Firmer support for the adaptation hypothesis was obtained with the last-position measure, by which the continuous presentation condition held a significant advantage over the standard suffix condition $[t(19)=2.19, p=.03]$, even though it fared less well than the no-suffix control condition $[t(19)=2.44, p=.02]$.

Performance in the triple suffix condition was virtually indistinguishable from performance in the standard suffix condition. The mean overall level of recall was .71 in the former condition and .70 in the latter. For list positions 1 through 9, the mean proportions of items recalled in the triple suffix condition were $.94, .84, .80, .69, .64$, $.60, .55, .58$, and .78 , respectively, and the corresponding means for the standard suffix conditions were .92 , $.83, .76, .67, .60, .57, .56, .56$, and .78 . Both the recency trend measure and the last-position measure showed virtually no difference between the two conditions. Thus, as has happened in previous research $(O . C$. Watkins \&
M. J. Watkins, 1982), we failed to replicate findings of a reduction in the suffix effect with the triple suffix procedure. In any event, the higher level of last-position recall obtained with the continuous presentation procedure was clearly not a consequence merely of the second and third postlist utterances of the irrelevant item.

\section{Experiment 5}

The results of Experiment 4 provide stronger evidence for the adaptation hypothesis than do those of the first three experiments. The purpose of the present experiment was to see whether even stronger evidence could be obtained by lowering the level of performance in the critical standard suffix and continuous presentation conditions. To this end, we replicated the procedure of Experiment 4 with the exception that the zero was presented in the same voice as the list items. By eliminating voice as a feature for discriminating the list items, the magnitude of the regular suffix effect should be increased (e.g., Morton et al., 1971, Experiments 14 and 15) and, perhaps as a result, any effects of adaptation would be more apparent.

\section{Method \\ The method was identical to that of Experiment 4, except for the manner in which the stimuli were recorded for presentation. The lists were as before, but this time the list items (1 through 9) and the irrelevant item (zero) were uttered in the same male voice. Each utterance lasted no longer than $450 \mathrm{msec}$ and was digitized and stored in a separate file on an Apple Macintosh 512 microcomputer; the digitizing apparatus and software were distributed by MacNifty (see Gibson, 1987, for a description). The timing of the item and list presentations was as in Experiment 4. Four versions of each list, one for each condition, were compiled and transferred to au- dio cassette tape. A separate tape was made for each of the four subject groups. \\ The subjects were 20 Rice University undergraduates.}

\section{Results and Discussion}

The main results are summarized in Figure 5. The overall level of recall was not as high as it was in Experiment 4. Also, a comparison of the no-suffix control condition and the standard suffix condition shows a somewhat more typical suffix effect in that, although it appeared to extend well back into the list, the effect was most pronounced toward the end of the list. The effect was indicated by both the recency-trend measure $[t(19)=4.79$, $p<.001]$ and the last-position measure $[t(19)=7.77$, $p<.001]$.

Consider now the results for the continuous presentation condition. The recency trend in this condition was only trivially, and not reliably, smaller than in the nosuffix control condition $[t(19)=.56, p>.10]$, and was greater than in the standard suffix condition $[t(19)=5.13$, $p<.001]$. Moreover, probability of last-item recall in the continuous presentation condition was greater than in the standard suffix condition $[t(19)=3.71, p<.001]$, even though it was lower than in the no-suffix control condition $[t(19)=5.39, p<.001]$. The results for both 


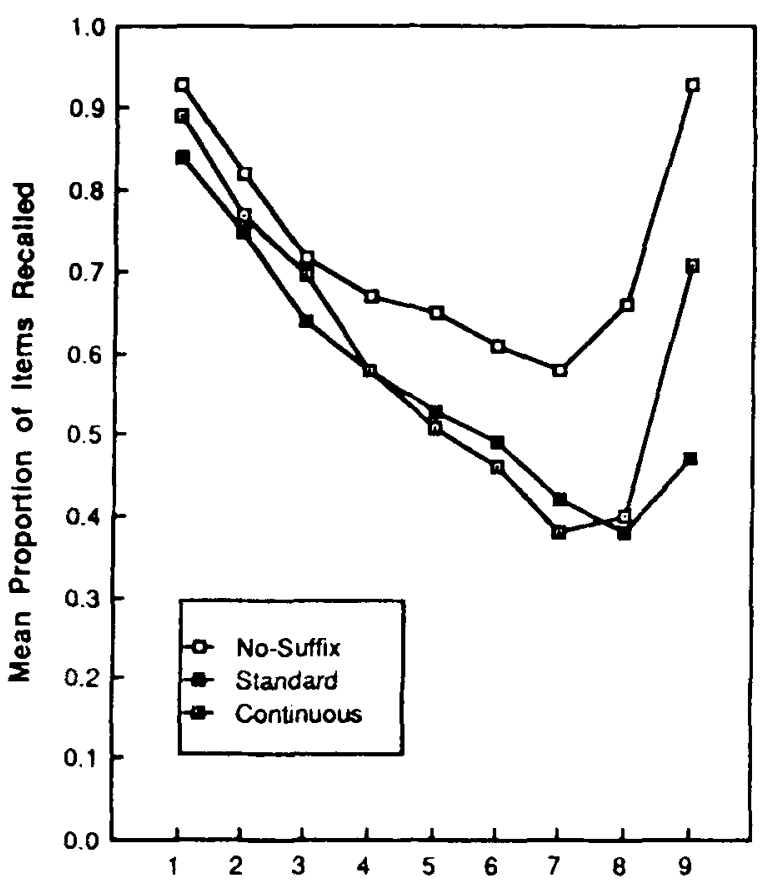

Serial Position

Figure 5. Mean proportion of items recalled in correct position as a function of serial position and suffix condition (Experiment 5).

measures of recency recall are therefore in accord with the notion that the irrelevant item is subject to adaptation.

Finally, the results for the triple suffix condition were again similar to those for the standard suffix condition. The mean level of overall recall for the triple suffix was .61 , and for the single suffix it was .57 ; the difference was not reliable $[t(19)=1.09, p>.10]$. The recall probabilities for Positions 1 through 9 were $.91, .80, .70, .62$, $.57, .55, .45, .41$, and .50 for the triple suffix condition, and $.84, .75, .64, .58, .53, .49, .42, .38$, and .47 for the standard suffix condition. Neither the recency-trend measure nor the last-position measure showed a reliable difference between these conditions $[t \mathrm{~s}(19)=.05$ and .50 , respectively, $p>.10$ in both cases]. Moreover, the triple suffix condition yielded a recency trend that was smaller than in either the continuous presentation condition or the no-suffix control condition $[t \mathrm{~s}(19)=4.38$ and 4.90 , respectively, $p<.001$ in both cases], and the level of last-position recall was lower than in either of the latter conditions $[t(19)=3.50, p<.01$, and $t(19)=7.58$, $p<.001$, respectively].

\section{Experiment 6}

In the concluding experiment of the series we sought to check whether the findings of Experiments 4 and 5 would hold up with a between-subjects design. In light of the findings of the first experiment, we had assumed in designing Experiments 2 through 5 that performance in a given condition would change only modestly over the course of the experimental session. We therefore thought a within-subjects design would increase our chances of discerning differences between conditions. It is possible, however, that there was transfer, even differential transfer, between conditions in the previous experiments. The between-subjects design of the present experiment precludes the possibility of such confounds.

A more particular question addressed in this experiment was whether the adaptation observed in the continuous presentation condition would persist beyond the point at which the stream of zeros ceased. In other words, we wanted to know whether adaptation would carry over from the continuous suffix condition to a standard suffix condition given immediately afterward. To the extent that our measures of recency recall in such a condition resemble those for the continuous presentation condition, adaptation could be said to persist beyond the duration of the continuous presentation condition; to the extent that these measures resemble those obtained for subjects in the standard suffix group, which had not experienced continuous presentation of the suffix, adaptation could be said to be confined to the duration of the continuous presentation condition.

\section{Method}

The subjects were 60 Rice University undergraduates. Some were tested 2 or 3 at a time, others individually. They were assigned to three groups in a way that was random within the constraints that each group include 20 subjects and that those tested be assigned to the same group. The groups may be referred to as the control, or no-suffix, group; the standard suffix group; and the continuous presentation/standard suffix group. Subjects in the no-suffix and standard suffix groups each received one set of 21 lists, the first of which was considered a practice list. Those in the continuous presentation/standard suffix group received two sets of 21 lists, one of which was used in the continuous presentation condition and the other in the standard suffix condition.

The lists were random permutations of the digits 1 to 9 , spoken at the rate of one every second, exactly as in the previous five experiments. In fact, the recordings of the two sets of lists were taken directly from those used in Experiment 5 . Within both the no-suffix group and the standard group, half of the subjects received one set and half received the other set. Within the continuous presentation/standard suffix group, half of the subjects received one set of lists in the continuous presentation condition and the other set in the standard suffix condition; for the other half of the subjects, these sets were reversed. Thus, the data for each of the four conditions (no-suffix, standard suffix, continuous presentation, and standard suffix after continuous presentation) were based on one set of 20 lists presented to 10 subjects and another set of 20 lists presented to 10 other subjects. We should note that we did not feel justified in presenting more than 20 lists (plus 1 practice list) in each condition because the continuous presentation condition is extraordinarily stressful.

\section{Results}

The results are summarized in Figure 6. The first point to note is that, relative to the no-suffix control condition, the standard suffix procedure reduced recall for the last few serial positions. This suffix effect was shown to be 


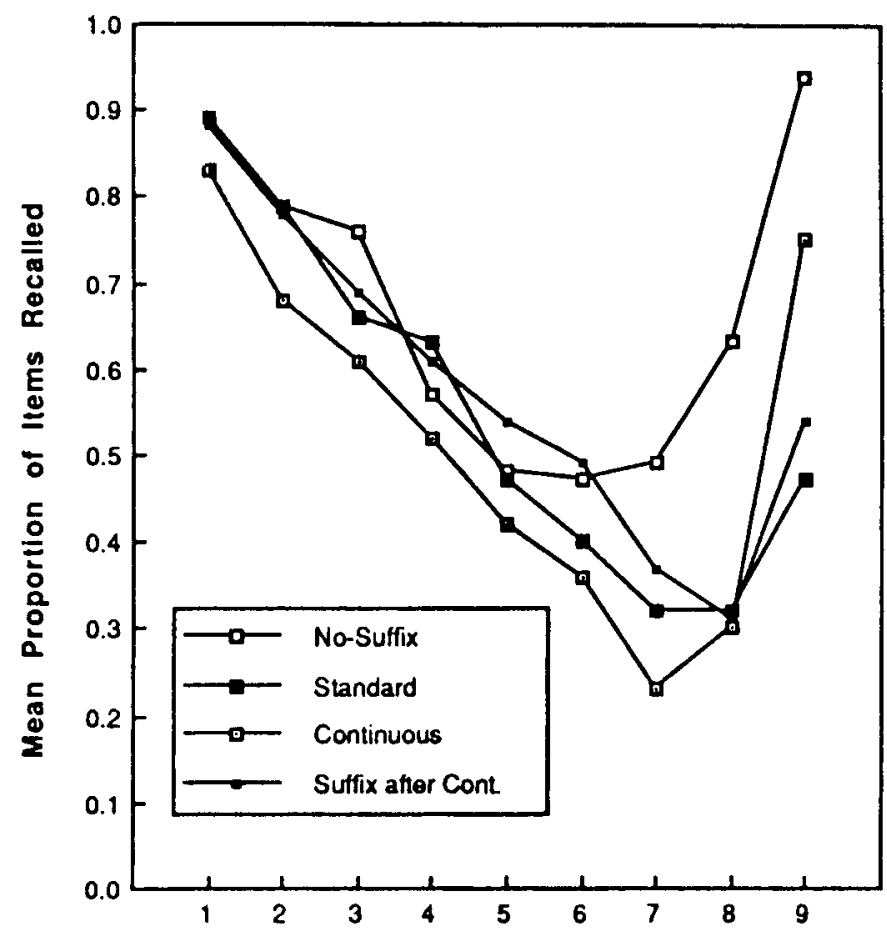

Serial Position

Figure 6. Mean proportion of items recalled in correct position as a function of serial position and suffix condition (Experiment 6).

statistically reliable with each of our measures of recency recall [for the recency-trend measure, $t(38)=4.30$, $p<.001$; for the last-position measure, $t(38)=7.90$, $p<.001]$.

More importantly, we replicated the findings of the previous two experiments of adaptation to the suffix item. Thus, both measures showed recency recall to be more pronounced in the continuous presentation condition than in the standard suffix condition [for the recency-trend measure, $t(38)=6.24, p<.001$; for the last-position measure, $t(38)=3.51, p=.001]$. Compared to the nosuffix control condition, the continuous presentation condition showed a trivially stronger recency effect $[t(38)=$ $0.86, p>.10]$, but a lower level of recall at the final position $[t(38)=3.57, p<.001]$. Clearly, the evidence obtained in Experiments 4 and 5 for adaptation to the suffix item was not an artifact of the within-subjects design.

We consider now whether the adaptation shown in the continuous presentation condition was critically dependent on the continuous stream of suffix items having occurred during the presentation of the to-be-remembered lists, or whether it would also have arisen if the continuous stream had been presented immediately beforehand. The question turns on whether the recency recall in the suffix condition that was given directly following the continuous presentation condition more closely resembles recency recall in the standard suffix condition than recency recall in the continuous presentation condition. As is evident from Figure 6 , it closely resembled recency recall in the standard suffix condition. The recency trend was very slightly more pronounced and the level of recall at the last position was slightly higher following continuous presentation of the suffix item, but by neither measure was the difference statistically significant $[t \mathrm{~s}(38)=$ 0.31 and 0.82 , respectively, $p>.10$ in both cases]. On the other hand, within-subject comparisons showed that recency was significantly less pronounced in the suffix condition following the continuous presentation condition than in the continuous presentation condition itself [for the recency-trend measure, $t(19)=4.92, p<.001$; for the last-position measure, $t(19)=4.94, p<.001$ ]. This experiment therefore provides no evidence that the adaptation caused by the continuous stream of suffix-item presentations persists once the stream stops.

Finally, we should mention that level of recall in the prerecency positions (i.e., through the first seven serial positions) was somewhat lower in the continuous presentation condition than in the other conditions. We cannot draw firm conclusions about this finding because the inferential analyses were inconclusive. In particular, prerecency recall in the continuous presentation condition was not reliably different from that in the standard suffix condition $[t(38)=1.20, p=.24]$. It was reliably different from that in the suffix condition following the continuous presentation condition $[t(19)=3.06$, 
$p<.01]$, but this result could be due merely to improvement with practice rather than to the suspension of the continuous presentation schedule. In any event, whatever impairment in prerecency recall occurs in the continuous presentation condition throws into bolder relief the superiority of this condition over the standard suffix condition in last-position recall.

Taken together, the results of Experiments 4-6 show comparatively clear evidence of adaptation to a nominally irrelevant item. Specifically, they show that when lists of verbal items are read aloud for serial recall, an irrelevant item tends to be more detrimental to the recall of the recency portions of the lists when uttered once immediately after each list presentation than when repeated in an unbroken stream extending through the list presentations and the recall intervals between them. This result holds whether recency recall is indexed by the trend in recall over the last three positions within a list or by level of recall at only the last position. By keeping the clock ticking, as it were, we seem to have achieved partial adaptation to the suffix item.

\section{GENERAL DISCUSSION}

The experiments reported here lend some support to the notion that the detrimental effect that a nominally irrelevant suffix item has on the recall of the last one or two items of a to-be-remembered list can be attenuated with repeated exposure to the irrelevant item. Experiment 1 showed a decline in the suffix effect across the course of a sequence of lists. Although slight, the decline took the form of an increment in recall in the suffix condition rather than a decrement in recall in the control condition, which is consistent with the hypothesis that subjects adapted to some degree to the suffix item. In Experiments 2 and 3 the irrelevant item was presented after each list item, rather than after just the last one. Compared with the standard suffix condition, this through-list condition yielded a stronger recency trend, although overall level of recall was depressed and absolute level of recall was nowhere higher than in the standard suffix condition. In the remaining three experiments we pursued the strategy of massing the suffix presentations a step further by presenting the irrelevant item in a steady stream that continued uninterrupted throughout the presentation and test phases alike. The result was a noticeably enhanced recency trend and a higher probability of recall for the last item within a list.

From some perspectives, the results of our experiments are surprising. For one thing, reducing the detrimental effect of an irrelevant item by intensifying its schedule of presentation is in some sense paradoxical. Also, previous research has clearly shown the detrimental effect of an irrelevant item presented in the suffix position to be robust and not easily modified. And in contrast to previous exceptions to this rule, the attenuation of the effect found in the present experiments was not the result of a physical distinction between the suffix item and the list items.

From another perspective, our evidence for adaptation is unsurprising. If a stimulus occurs over and over in regular and rapid succession, then any given occurrence carries minimal information and so, from a functional standpoint, does not justify control of our attention. In the real world beyond the laboratory, not only are we able to ignore repeating stimuli when we wish to, but it is difficult to keep our attention on them even when we try (see Davies \& Parasuraman, 1982). Hence, we might have expected an even greater enhancement of recency from intensive exposure to the irrelevant item than we did in fact obtain. After all, even our unrelenting continuous presentation procedure did not fully restore recency recall to the level observed in the absence of any irrelevant stimuli.

\section{REFERENCES}

Baddeley, A., Hull, A. (1979). Prefix and suffix effects: Do they have a common basis? Joumal of Verbal Learning \& Verbal Behavior, $18,129-140$.

Balota, D. A. \& Engle, R. W. (1981). Structural and strategic factors in the stimulus suffix effect. Journal of Verbal Leaming \& Verbal Behavior, 20, 346-357

BjoRk, R. A., WhitTen, W. B. (1974). Recency-sensitive retrieval processes in long-term free recall. Cognitive Psychology, 6, 173-189.

Broadbent, D. E. (1952). Listening to one of two synchronous messages. Quarterly Journal of Experimental Psychology, 4, 51-55.

Crowder, R. G. (1967). Prefix effects in immediate memory. Canadian Journat of Psychology, 21, 450-461.

Crowder, R. G. (1969). Improved recall for digits with delayed recall cues. Journal of Experimental Psychology, 82, 258-262.

Crowder, R. G. (1978). Mechanisms of auditory backward masking in the stimulus suffix effect. Psychological Review, 85, 502-524.

Crowder, R. G., \& Morton, J. (1969). Precategorical acoustic storage (PAS). Perception \& Psychophysics, 5, 365-373.

DAllett, K. M. (1965). "Primary memory": The effects of redundancy upon digit repetition. Psychonomic science, 3, 237-238.

Davies, D. R., PARAsuraman, R. (1982). The psychology of vigilance. London: Academic Press.

Gibson, J. M. (1987). Using digitized auditory stimuli on the Macintosh computer. Behavior Research Methods, Instruments, \& Computers, 19, 257-259

Glanzer, M., \& Cunitz, A. R. (1966). Two storage mechanisms in free recall. Journal of Verbal Leaming \& Verbal Behavior, 5, 351-360.

GreenberG, S. N., \& ENGLe, R. W. (1983). Voice changes in the stimulus suffix effect: Are the effects structural or strategic? Memory \& Cognition, 11, 551-556.

Hitch, G. J. (1975). The role of attention in visual and auditory suffix effects. Memory \& Cognition, 3, 501-505.

Kahneman, D., \& Henik, A. (1981). Perceptual organization and at tention. In M. Kubovy \& J. R. Pomeranz (Eds.), Perceptual organization (pp. 181-212). Hillsdale, NJ: Erlbaum.

Lorch, E. P., ANderson, D. R., \& Well, A. D. (1984). Effects of irrelevant information on speeded classification tasks: Interference is reduced by habituation. Journal of Experimental Psychology: Human Perception \& Performance, 10, 850-864.

Morton, J. M. (1976). Two mechanisms in the stimulus suffix effect. Memory \& Cognition, 4, 144-149.

Morton, J., Crowder, R. G., \& Prussin, H. A. (1971). Experiments with the stimulus suffix effect. Joumal of Experimental Psychology, 91, 169-190.

Morton, J., Marcus, S. M., \& OTtley, P. (1981). The acoustic correlate of "speechlike": A use of the suffix effect. Joumal of Experimental Psychology: General, 10, 568-593. 
Penney, C. G. (1985). Elimination of the suffix effect on preterminal list items with unpredictable list length: Evidence for a dual model of suffix effects. Journal of Experimental Psychology: Learning, Memory, \& Cognition, 11, 229-247.

Postman, L., \& Phillups, L. W. (1965). Short-term temporal changes in free recall. Quarterly Journal of Experimental Psychology, 17, 132-138.

Reisberg, D., BAron, J., \& Kemler, D. G. (1980). Overcoming Stroop interference: The effects of practice on distractor potency. Journal of Experimental Psychology: Human Perception \& Performance, 6, $140-150$

Routh, D. A., Frosdick, R. M. (1978). The basis and implications of the restoration of a recency effect in immediate serial recall. Quarterly Journal of Experimental Psychology, 30, 201-220.

Salamé, P., Baddeley, A. D. (1982). Disruption of short-term memory by unattended speech: Implications for the structure of working memory. Journal of Verbal Learning \& Verbal Behavior, 21, 150-164.

STroop, J. R. (1935). Studies of interference in serial verbal reaction. Journal of Experimental Psychology, 18, 643-662.

Treisman, A. M. (1964). Verbal cues, language, and meaning in selective attention. American Joumal of Psychology, 77, 206-219.

TzENG, O. J. L. (1973). Positive recency effect in a delayed free recall. Journal of Verbal Learning \& Verbal Behavior, 12, 436-439.

Waters, W. F., McDonald, D. G., \& Koresko, R. L. (1977). Habituation of the orienting response: A gating mechanism subserving selective attention. Psychophysiology, 14, 228-236.

WATKINS, M. J. (1989). Willful and nonwillful determinants of memory. In H. L. Roediger III \& F. I. M. Craik (Eds.), Varieties of memory and consciousness: Essays in honour of Endel Tulving (pp. 59-72). Hillsdale, NJ: Erlbaum.

WAtKINS, O. C., \& WATKINS, M. J. (1980). Echoic memory and voice quality: Recency recall is not enhanced by varying presentation voice. Memory \& Cognition, 8, 26-30.

WATKINS, O. C., \& WATKINS, M. J. (1982). Lateral inhibition and echoic memory: Some comments on Crowder's (1978) theory. Memory \& Cognition, 10, 279-286.

\section{NOTE}

1. To ensure that this interaction was not the product of a ceiling effect, the 864 list recalls (9 lists from each of 96 subjects) within each condition-block combination were assigned to two sets, one for lowscoring recalls (0-4 items correctly recalled) and one for high-scoring recalls (5-9 items correctly recalled). The linear component of trend for the condition-block interaction turned out to be similar for the two sets of data, which suggests that this effect for the combined data was not the result of a ceiling effect.

\begin{tabular}{|c|c|c|}
\hline \multicolumn{3}{|c|}{$\begin{array}{c}\text { APPENDIX } \\
\begin{array}{c}\text { Mean Recency-Trend and Last-Position Scores } \\
\text { for Each Condition of Experiments 1-6 }\end{array}\end{array}$} \\
\hline Condition & Recency-Trend & Last-Position \\
\hline $\begin{array}{l}\text { Experiment } 1 \\
\text { Suffix }\end{array}$ & & \\
\hline $\begin{array}{l}\text { Block } 1 \\
\text { Block } 2 \\
\text { Block } 3\end{array}$ & $\begin{array}{l}.11 \\
.09 \\
.10\end{array}$ & $\begin{array}{l}.45 \\
.47 \\
.54\end{array}$ \\
\hline $\begin{array}{l}\text { Control } \\
\text { Block } 1 \\
\text { Block } 2 \\
\text { Block } 3\end{array}$ & $\begin{array}{l}.39 \\
.38 \\
.36\end{array}$ & $\begin{array}{l}.89 \\
.90 \\
.88\end{array}$ \\
\hline $\begin{array}{l}\text { Experiment } 2 \\
\text { Through-list } \\
\text { Standard suffix } \\
\text { Control }\end{array}$ & $\begin{array}{l}.25 \\
.08 \\
.31\end{array}$ & $\begin{array}{l}.54 \\
.57 \\
.95\end{array}$ \\
\hline $\begin{array}{l}\text { Experiment } 3 \\
\text { Through-list } \\
\text { Standard suffix } \\
\text { Control }\end{array}$ & $\begin{array}{l}.32 \\
.15 \\
.47\end{array}$ & $\begin{array}{l}.55 \\
.51 \\
.89\end{array}$ \\
\hline $\begin{array}{l}\text { Experiment } 4 \\
\text { Continuous suffix } \\
\text { Triple suffix } \\
\text { Standard suffix } \\
\text { Control }\end{array}$ & $\begin{array}{l}.31 \\
.23 \\
.22 \\
.27\end{array}$ & $\begin{array}{l}.85 \\
.78 \\
.78 \\
.91\end{array}$ \\
\hline $\begin{array}{l}\text { Experiment } 5 \\
\text { Continuous suffix } \\
\text { Triple suffix } \\
\text { Standard suffix } \\
\text { Control }\end{array}$ & $\begin{array}{l}.33 \\
.05 \\
.05 \\
.35\end{array}$ & $\begin{array}{l}.71 \\
.50 \\
.47 \\
.93\end{array}$ \\
\hline $\begin{array}{l}\text { Experiment } 6 \\
\text { Continuous } \\
\text { Suffix after continuous } \\
\text { Standard suffix } \\
\text { Control }\end{array}$ & $\begin{array}{l}.51 \\
.17 \\
.15 \\
.45\end{array}$ & $\begin{array}{l}.75 \\
.54 \\
.47 \\
.94\end{array}$ \\
\hline
\end{tabular}

Note-Last-position score is defined as the proportion of items recalled from Serial Position 9, and the recency-trend score as the proportion of items recalled from Serial Position 9 minus the proportion recalled from Serial Position 7.

(Manuscript received March 4, 1988;

revision accepted for publication May 1, 1989.) 